\title{
Work-to-Family enrichment and Job Involvement: The Mediating Role of Organizational Identification
}

\author{
Lin Qiu \\ School of Business Administration, South China University of Technology, Guangzhou, China \\ linqiu@scut.edu.cn
}

Keywords: Work-to-Family enrichment, organizational identification, job involvement, mediation.

\begin{abstract}
The last two decades have seen a dramatic increase in research focusing on the work-family interface. However, the study of work-family enrichment and its work-related consequences have been surprisingly neglected. The present study investigates the impact of work-to-family enrichment (WFE) as perceived by employees on their job involvement by focusing on the mediating role of organizational identification (OID). The results from a field survey of 207 employees in China provide full support for our hypotheses, indicating that perceived WFE is positively related to both OID and job involvement; this relationship is also mediated by organizational identification. The theoretical and managerial implications of these findings are discussed.
\end{abstract}

\section{Introduction}

Work and family are the most central and salient domains in one's life. However, the majority of work-family research has focused on the negative aspect of work-family interface (e.g. work-family conflict; see a review by Eby, Casper, Lockwood, Bordeaux, \& Brinley, 2005)[1]. In line with the positive psychology movement, researchers recently are beginning to shift their focus to the positive side of work-family interface-work-family enrichment, which is defined as the extent to which experiences in one role improve the quality of life in the other role (Greenhaus \& Powell, 2006)[2]. This stream of research is important in that enrichment and conflict have been identified as two distinct constructs but not simply two ends of the same continuum (Carlson et al., 2006)[3], suggesting our knowledge of conflict tells us very little about enrichment. Also, the emerging focus on work-family enrichment supplements the dominant conflict perspective by identifying new ways of cultivating human resources.

Although existing demonstrates that work-family enrichment has positive effects on employee satisfaction, health, commitment and performance (c.f., Carlson, Ferguson, Kacmar, Grzywacz, \& Whitten, 2011; McNall, Nicklin, \& Masuda, 2010)[4, 5], as an understudied area, more research is still needed on how enrichment is related to work-related outcomes to inform organizations of its importance (Carlson et al. 2011)[4]. In particular, no research to date has investigated effects of work-family enrichment on two important work-related variables: organizational identification (OID) and job involvement. What's more, researchers recently argue that there is limited non-western sampling in work-family literature (Kossek, Baltes, \& Matthews, 2011)[6]. Thus, the first purpose of this study is to substantiate the impact of work-to-family enrichment on OID and job involvement among Chinese employees. In addition, to echo a recent call to explore the underlying mechanisms and processes by which work-family enrichment exerts its influence on the outcomes (McNall et al., 2010)[5], the present study also aims to examine the indirect effects of work-to-family enrichment on job involvement through OID. A graphical depiction of the model is presented in Figure 1.

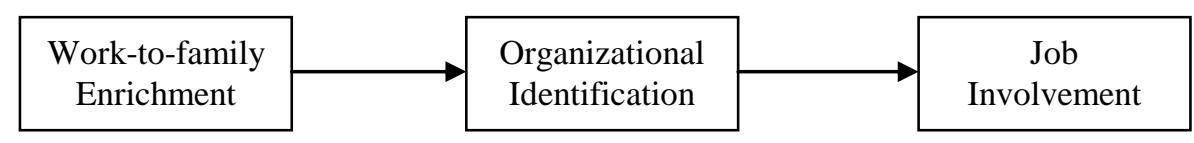

Figure. 1 The mediating effects of organizational identification on the relationship between work-to-family enrichment and job involvement 


\section{Theory and hypotheses}

The experience of work-family enrichment is traditionally described using role theory, which suggests that participation in multiple roles can produce positive outcomes for individuals. Work-family enrichment is bidirectional in that work potentially enriches family life (work-to-family enrichment; WFE) and family life also potentially enriches work (family-to-work enrichment; FWE) [2]. Recent studies have found that the role from which enrichment originates is more strongly related to various outcomes than the role from which the enrichment is received (McNall et al., 2010)[5]. And this study aims to explore the effects of enrichment on two work domain variables (i.e., organizational identification and job involvement). Therefore, the present research focuses on WFE.

Organizational identification (OID) has been viewed as a desirable individual attachment to the employing organization. From an employee perspective, OID satisfies a number of individual psychosocial needs, such as safety, affiliation, self-enhancement and meaning in one's life (Dutton, Dukerich, \& Harquail, 1994)[7]. From an organizational perspective, employees identifying with their organization tend to internalize organizational attributes as their own, and think and act congruently with the organization's goal, and in turn, these positive employee attitudes and behaviors contribute to an organization's financial performance (van Dick et al., 2006)[8].

Concurrently, job involvement is considered to be a key factor influencing important individual and organizational outcomes. Job involvement refers to 'the degree to which one is cognitively preoccupied with, engaged in, and concerned with one's present job (Paullay et al., 1994, p. 224)[9]. It influences the degree to which a person supports organizational goals, and thus advancing productivity and efficiency of an organization (Brown 1996)[10]. Hence, it is crucial to understand the association between WFE, OID and job involvement.

Although, until now the relationship between WFE and OID or job involvement has received little empirical attention, social exchange theory (Blau, 1964)[11] can be employed to explain these relationships. This theory states that individuals seem to reciprocate in the form of more favorable attitudes towards the domain that is perceived to be the originator of the resource generation. Work-family enrichment theory proposes that resources created in the workplace can be applied to the family domain - even though the environments and situations are different. The application of such workplace-created resources at home can help employees generate positive affect at home and promote their family performance. According to social exchange theory, employees will reciprocate the organization by identifying its goals and missions or/and getting more involved into their jobs when they perceive their work resources provided by the organization have enriched their family life. Thus, this study formulates the following hypotheses:

Hypothesis 1: WFE is positively related to OID.

Hypothesis 2: WFE is positively related to job involvement.

Job involvement has been conceptualized in terms of individuals' organizational identification. For example, Kanungo (1982) defines job involvement as the degree to which individuals identify with, or give to, the job[12]. Specific attributes of the work situation itself may result in employees being more involved in their jobs. Empirical evidence has verified that organizational identification is substantially associated with employee job involvement (Carmeli et al., 2007)[13]. Combined with Hypothesis 1, it is reasonable to argue job involvement mediates the relationship between OID and job involvement. That is, employees' perceptions of WFE affect their organizational identification and thereby influence their job involvement.

Hypothesis 3: Job involvement mediates the relationship between OID and job involvement.

\section{Method}

Participants and Procedures. The participants in this study were full-time employees in southern China. In all, 207 (81.3\%) participants completed all sections of the survey. Out of these participants, $48.3 \%$ are female, with the majority $(62.8 \%)$ being married. Approximately $63.6 \%$ were 40 years old or less. 
Measures. Work-to-family enrichment (WFE) was measured using the nine items developed by Carlson et al. (2006)[3]. Cronbach's alpha for this scale was .84.

Organizational identification (OID) was measured using the four-item scale from Carmeli et al. (2007)[13]. Cronbach's alpha for this scale was .72.

Job involvement was measured by using six items which were taken from Kanungo's (1982) Job Involvement Questionnaire[12]. Cronbach's alpha for this scale was .81.

The control variables were position $(1=$ non-supervisory, $2=$ first-level supervisor, $3=$ middle-level manager, $4=$ top-level manager $)$ gender $(0=$ male, $1=$ female $)$, age $(1=40$ or less, $2=$ more than 40 ), and marriage status ( $1=$ single, $2=$ married $)$.

\section{Results}

Table 1 depicts descriptive statistics and correlations for the variables examined. Job involvement was positively correlated with WFE $(\mathrm{r}=.23, \mathrm{p}<.01)$ and OID $(\mathrm{r}=.39, \mathrm{p}<.01)$. Moreover, WFE was positively correlated with OID $(\mathrm{r}=.20, \mathrm{p}<.01)$. These results provide initial support for the hypotheses.

Table 1 Descriptive statistics and correlations

\begin{tabular}{|l|c|c|c|c|c|c|c|c|c|}
\hline & Mean & $S D$ & 1 & 2 & 3 & 4 & 5 & 6 & 7 \\
\hline 1. Position & 1.97 & .91 & 1 & & & & & & \\
\hline 2. Gender & .51 & .61 & $.25^{* *}$ & 1 & & & & & \\
\hline 3. Age & 1.27 & .44 & $.53^{* *}$ & $.25^{* *}$ & 1 & & & & \\
\hline 4. Marriage Status & 1.66 & .53 & $.25^{* *}$ & $.14^{*}$ & $.37^{* *}$ & 1 & & & \\
\hline 5. WFE & 3.83 & .69 & .02 & .10 & .09 & $.20^{* *}$ & 1 & & \\
\hline 6. OID & 3.67 & .68 & $.15^{*}$ & $.16^{*}$ & .12 & $.19^{* *}$ & $.20^{* *}$ & 1 & \\
\hline 7. Job Involvement & 3.09 & .75 & $.20^{* *}$ & .01 & .11 & .04 & $.23^{* *}$ & $.39^{* *}$ & 1 \\
\hline
\end{tabular}

Notes: $* \mathrm{p}<.05 ; * * \mathrm{p}<.01 ; \mathrm{WFE}=$ work-to-family enrichment; OID = Organizational identification.

This study used hierarchical multiple regressions to test the Hypotheses. In all analyses, the control variables of management rank, gender, age and number of children under the age of 18 were entered into the regression model first, and then the primary study variables. Baron and Kenny (1986) [14] proposed a four-step approach to establish the conditions for mediation: (a) the independent and mediating variables must be significantly related; (b) the independent and dependent variables must be significantly related; (c) the mediator and dependent variable must be significantly related; and (d) the relationship between the independent variable and dependent variable should be non-significant or weaker when the mediator is added.

Table 2 presents results of the regression analyses. As can be seen, after controlling for several demographic variables, OID was significantly related to WFE (Model $2 ; \beta=.16, p<.05$ ). Thus, Condition (a) for the mediation effect was met. Job involvement was also significantly related to WFE (Model $4 ; \beta=.24, p<.01$ ), satisfying Condition (b). OID was positively related to job involvement (Model 5; $\beta=.37, \mathrm{p}<.001$ ). Thus, Condition (c) was met. Further, after OID was taken into account, the effect of WFE on job involvement remained significant but decreased in magnitude (Model 5; $\beta=.19, \mathrm{p}<.01$ ), which suggests a partial mediation effect. Thus, Condition (d) was satisfied.

Table 2 Regression results of the mediation model

\begin{tabular}{|l|c|c|c|c|c|}
\hline \multirow{2}{*}{} & \multicolumn{2}{|c|}{ OID } & \multicolumn{3}{c|}{ Job Involvement } \\
\cline { 2 - 6 } & Model 1 & Model 2 & Model 3 & Model 4 & Model 5 \\
\hline Position & .09 & .10 & $.21^{*}$ & $.22^{* *}$ & $.18^{*}$ \\
\hline Gender & .11 & .10 & .02 & -.01 & .04 \\
\hline
\end{tabular}




\begin{tabular}{|l|c|c|c|c|c|}
\hline Age & -.01 & -.02 & .04 & .03 & .03 \\
\hline Marriage Status & $.16^{*}$ & .13 & -.10 & $-.16^{*}$ & $-.20^{* * *}$ \\
\hline WFE & & $.16^{*}$ & & $.26^{* * *}$ & $.19^{* *}$ \\
\hline OID & & & & & $.36^{* * *}$ \\
\hline $\mathrm{R}^{2}$ & .06 & .09 & .05 & .11 & .23 \\
\hline $\mathrm{F}$ & $3.25^{*}$ & $3.72^{* *}$ & 2.70 & $5.12^{* * *}$ & $10.04^{* * *}$ \\
\hline
\end{tabular}

Notes: $* \mathrm{p}<.05 ; * * \mathrm{p}<.01 ; * * * \mathrm{p}<.001 ; \mathrm{WFE}=$ work-to-family enrichment; OID = Organizational identification.

To provide a more rigorous test of the mediation effect, we used Preacher and Hayes's (2004) ${ }^{[15]}$ macro to test the indirect effect with 5,000 bootstrap samples. Results showed that the $95 \%$ confidence interval of the indirect effect estimate $[.01, .13]$ did not contain zero, indicating that the indirect effect was significant. Taken together, Hypotheses 1, 2, and 3 were supported, that is, OID partially mediated the relation between WFE and job involvement.

\section{Discussion}

The current study addresses a key outcome of the work-family interface (i.e., WFE), and also investigates a critical component of employee-organization relationship (i.e., organizational identification) and an important form of employee attitudes towards job (i.e., job involvement) to fully capture the outcomes of positive work-family interactions. Integrating work-family enrichment theory and the social exchange perspective, this study extended organizational identification to represent a mediating mechanism between WFE perceived by employees and their job involvement. The theoretical and managerial implications of our findings are discussed in the sections that follow.

Results of the present study empirically demonstrate for the first time that employees' perceived WFE is associated with to two important work-related variables: OID and job involvement, responding to the call from Carlson et al. (2011)[4] to explore the outcomes of enrichment in the work domain. OID can provide cohesion - a key ingredient of organizational success and it has been believed that highly job-involved employees will put forth substantial effort towards the achievement of organizational objectives and be less likely to turnover (Paullay et al., 1994)[9]. Therefore, the positive synergies between work and family should draw attention of scholars and practitioners as a facilitator to organizational success and individual personal growth.

Drawing on social exchange theory, this study contributes to the work-family interface, OID, and job involvement literatures by showing that OID - a type of positive psychological state as an important intervening mechanism-mediates the relationship between WFE and employees' job involvement. The results from the current study may encourage future researchers to address the impact of work-family enrichment on employee outcomes by focusing on the mediating roles of other positive psychological states (e.g., self-efficacy, self-esteem). In addition, this study has also answered the call from Kossek et al. (2011) [6] to use non-Western samples. Thus, our research extended the Caucasian samples from the past findings to a different cultural context.

Our work suggests that organizations and managers can spur employees' OID and job involvement through enhancing their perception of WFE. There are many alternatives for managers who may be interested in facilitating employees' OID and job involvement, including providing more work resources in the workplace such as family-friendly policies, supervisor support, and job autonomy, nourishing positive and caring climates in the workplace, creating a cohesive team spirit so that staff will feel they receive more organizational support.

\section{References}

[1] L.T. Eby, W.J. Casper, A. Lockwood, C. Bordeaux, A. Brinley, Work and family research in IO/OB: content analysis and review of the literature (1980-2002), Journal of Vocational Behavior 66 (2005) 124-197. 
[2] J.H. Greenhaus, G.N. Powell, When work and family are allies: A theory of work-family enrichment, Academy of Management Review, 31(2006) 72-92.

[3] D.S. Carlson, M.K. Kacmar, J.H. Wayne, J.G. Grzywacz, Measuring the positive side of the work-family interface: Development and validation of a work-family enrichment scale, Journal of Vocational Behavior, 68 (2006) 131-164.

[4] D.S. Carlson, M. Ferguson, K.M. Kacmar, J.G. Grzywacz, D. Whitten, Pay it forward: the positive crossover effects of supervisor work-family enrichment, Journal of Management, 37 (2011) 770-789.

[5] L.A. McNall, J.M. Nicklin, A.D. Masuda, A meta-analytic review of the consequences associated with work-family enrichment, Journal of Business and Psychology, 25 (2010) 381-396.

[6] E.E. Kossek, B.B. Baltes, R.A. Matthews, How work-family research can finally have an impact in organizations, Industrial and Organizational Psychology, 4 (2011) 352-369.

[7] Dutton, J. E., Dukerich, J. M., \& Harquail, C. V. (1994). Organizational image and member identification, Administrative Science Quarterly, 39, 239-263.

[8] R. Van Dick, M. Grojean, O. Christ, J. Wieseke, Identity and the extra-mile: Relationships between organizational identification and organizational citizenship behavior, British Journal of Management, 17 (2006) 283-301.

[9] I.M. Paullay, G.M. Alliger, E.F. Stone-Romero, Construct validation of two instruments designed to measure job involvement and work centrality, Journal of Applied Psychology, 79 (1994) 224-228.

[10] S.P. Brown, A meta-analysis and review of organizational research on job involvement. Psychological Bulletin, 120 (1996) 235-255.

[11]P.M. Blau, Exchange and Power in Social Life, New York: Wiley, 1964.

[12] R.N. Kanungo, Measurement of job and work involvement, Journal of Applied Psychology, 67 (1982) 341-349.

[13]A. Carmeli, G. Gilat, D.A. Waldman, The role of perceived organizational performance in organizational identification, adjustment and job performance, Journal of Management Studies, 44 (2007) 972-992.

[14] R.M. Baron, D.A. Kenny, The moderator-mediator variable distinction in social psychological research: Conceptual, strategic and statistical considerations, Journal of Personality and Social Psychology, 51(1986) 1173-1182.

[15] K.J. Preacher, A.F. Hayes, SPSS and SAS procedures for estimating indirect effects in simple mediation models, Behavior Research Methods, Instruments, and Computers, 36(2004) 717-731. 